\title{
Survey on Services of Cloud Computing
}

\author{
Tejaswini Kharat ${ }^{1}$, Shruti Kadam ${ }^{2}$ \\ Student, Computer Science Department of Engineering, DACOE, Karad, Maharashtra, India ${ }^{1,2}$
}

\begin{abstract}
The term cloud computing "Is a reset buzzword's in IT world". Cloud computing aimed at providing IT as a service to the cloud user on-demand basis with greater flexibility, availability, reliability and massive scalability with utility of computing mode. It is concept where a computer is created using internet with main purpose of utilizing share resources like computer, software and hardware etc. In general cloud computing is an internet based environment where you pay for resources that you use. The term cloud computing centralizing computation, it came in web backing in 1990's. This paper represent review of cloud computing concept also different kinds of services provide over the cloud computing, cloud infrastructure, security. However, the vulnerabilities of the infrastructure involved in cloud computing based on $\mathrm{m}$ - health system as well as problems and solutions in information security.
\end{abstract}

Keywords: Cloud Computing, Cloud services (IaaS, PaaS, SaaS), Complex network.

\section{INTRODUCTION}

The word cloud computing is formed by two concepts as cloud and computing. Cloud is a collection of complex, irregular network, huge storage devices, services required by the end user, interfaces and hardware component. Which are able to provide the services required by the end users over the internet based on user demand? Cloud is the Metaphor for internet computer network is composition of many computers connected which each other lines, such as a cables and connection. Switches and servers also connected in this manner.

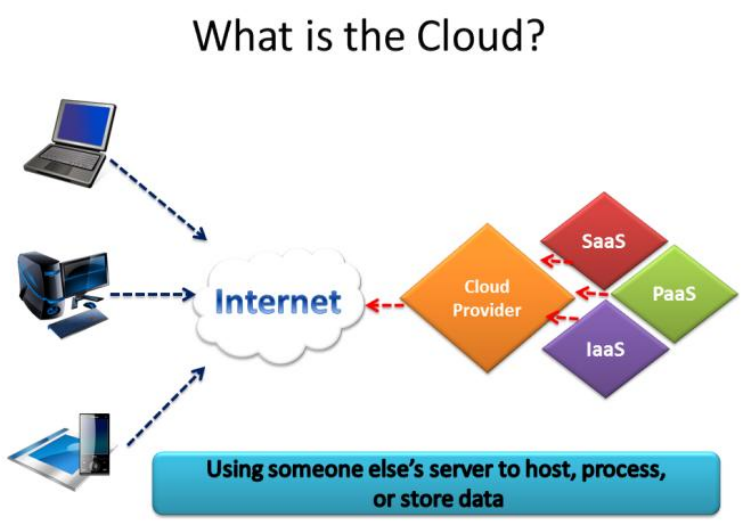

In computer technology, involved computing hardware and software, but must involve some form of the computer system.

Cloud computing means provide services from technologies through servers to the end users in flexible, efficient and irregular manner as they required. We can see multitenancy in cloud computing through different IT sectors companies shearing the same resources. Cloud services like social media such as Facebook, twitter, collaboration tools (Video Conferencing), document management. Change the way of service access deliver and understand the information.
Cloud computing are described into three types, based on the services:

Infrastructure as a service (IaaS)

Platform as a service (PaaS)

Software as a service (SaaS)

Fig. Evaluation of the cloud computing.

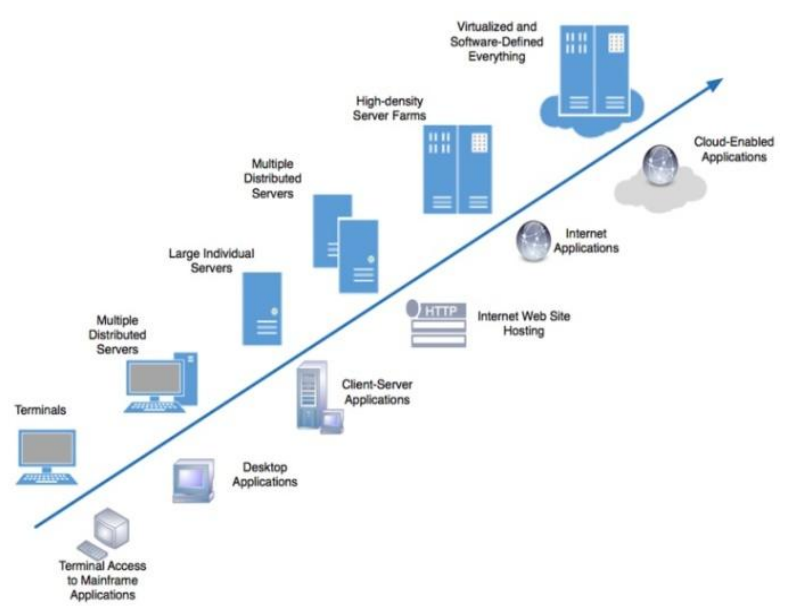

II. LITERATURE SURVEY

Cloud computing became popular in October 2007 when IBM and Google announced collaboration in the domain. These was followed by IBM's announce of the "Blue Cloud" effort [1]. Each cloud provides users with services at different level of abstraction. Which is referred to as services model in the NIST definition? These three service models are SaaS, IaaS and PaaS [2]. The concept of cloud based services is hierarchal built from bottom to top it order of IaaS, PaaS and SaaS. The core concern of security and the fashion of computing are not affected by level of abstraction [3]. The study of complex network is a young and active area of scientific research inspired study of real word networks each server has processing capacity each 
IARJSET

communication link has bandwidth capacity[4].Cloud B. PLATFORM AS A SERVICE (PaaS):

application programming interface (API) is a software It is the one of the type of cloud computing is based on the interface that let's your companies application plugged services. Inherently, multilane and nationally support into the cloud. This is perhaps the most important placed whole set of net services standard and usually delivered for standredlization [5].The term services in cloud with dynamic scaling. Dynamic scaling means computing is concept of being able to use reusable automatically up and down. Provide life cycle components across the users network. There are two main management - capabilities to manage all software components in client/server computing servers and development stages from planning, designing, to building thin/light clients [6]. Cloud data can be very large (eg.text and deployment, to testing and maintain.

based or scientific applications), unstructured or semi Some example of PaaS i.e. Platform as a service are structured and typically append - only with rare updates Google app engine, Herku, AppJet, Etelos, Qrimp and cloud data management an important research topic in force.com, Red Hat Open Shift. cloud computing [7].

\section{CLOUD COMPUTING SERVICE}

\section{A. A.INFRASTRUCTURE AS A SERVICE (IaaS):}

It is type of cloud computing based on services. Infrastructure of cloud computing can be established in many way. It depends on application and the way service providers choose to provide services to users. Keep billions of mobile devices in synchronous with social network, email system and PCs via the cloud - mobile data, rich media, messages, files and more. Cloud computing infrastructure is the combination of the software and hardware system. Scaling is applied to the infrastructure, so that it can automatically scale up and down as requirement of application.

For example: Mobile cloud infrastructure.

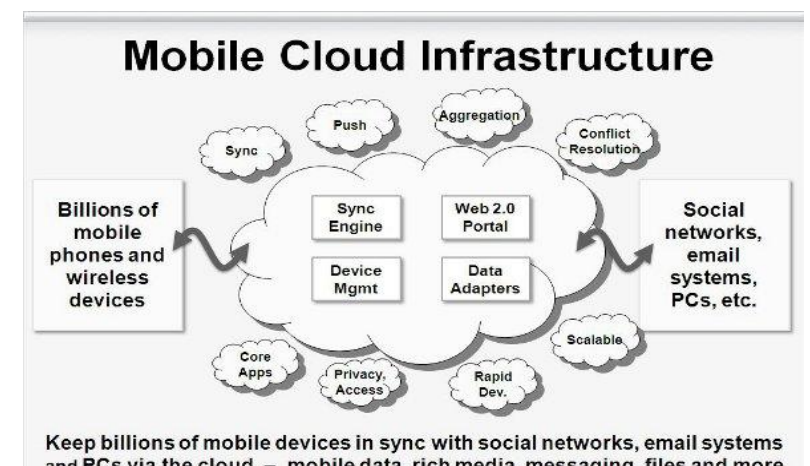

For example: Google compute engine, Rackspace services, Amazon AWS.

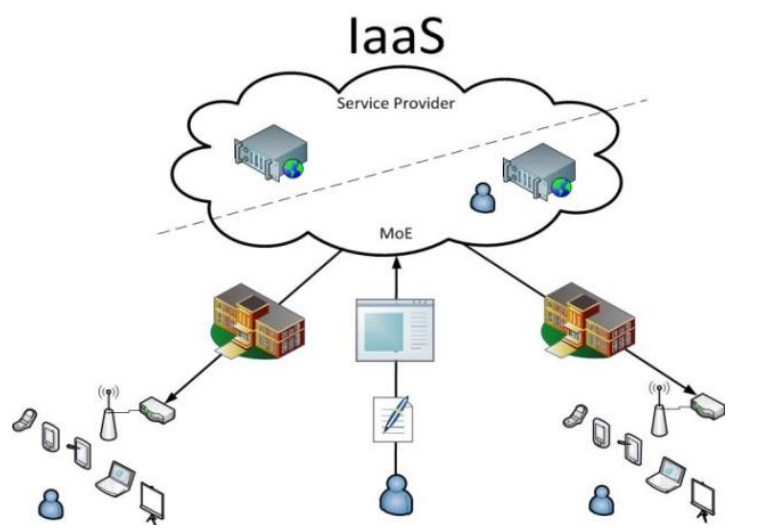

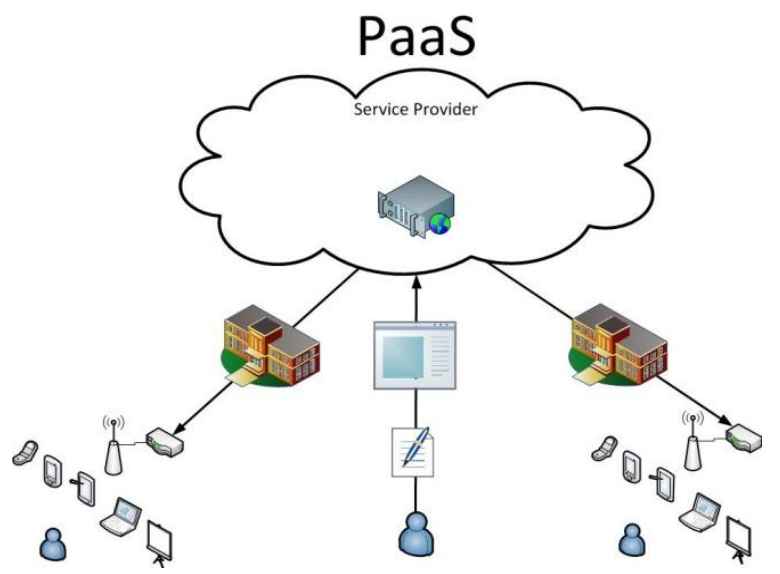

C.SOFTWARE AS A SERVICE (SaaS)

SaaS is type of the cloud computing, which is based on the services. Software as a service has a carried out by application service provider (ASPs) one of the first implementation of the cloud services was SaaS - business application handle by the provider and delivered as a service. Software as a service eliminates the need to install that and run application on individual computers.

For example: Google apps, Sales force, Workday, Concur, Citrix Go to Meeting, Cisco WebEx.

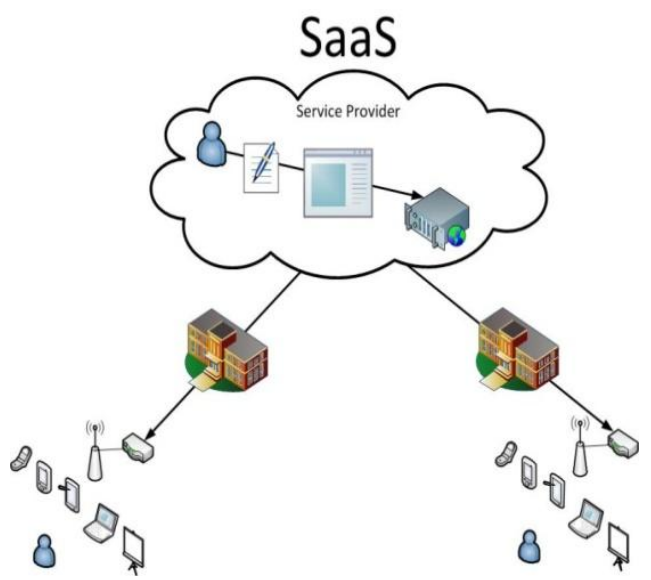

SECURITY SERVICE OF CLOUD COMPUTING:

Security is an important thing while considering concept of cloud computing. Security service of cloud computing involved three services: IaaS, PaaS, SaaS. 
IARJSET

\section{SECURITY SERVICE OF IAAS:}

It's focus on managing on the virtual machine. Provide authority to organization, to controls in place of regarding how virtual machine are created and spun down us avoiding uncontrolled access and potentially costly wastage. IaaS is a self-service model for accessing, monitoring and managing remote data centre infrastructure such as compute, storage, networking and networking services. IaaS based on consumption similar to electricity.

\section{SECURITY SERVICE OF PaaS:}

The primary focused of PaaS model on protecting the data. Web apps - it technique where by tools, scan build application for common security such as cross site scripting (Xss and SQL injection). PaaS providers provide those tools either free of charge or reduce the prize to customers. In PaaS encrypt the data whilst stored on the third party platform and to be aware of the regulatory issues that may apply to data availability in different geographies.

\section{SECURITY SERVICE OF SaaS:}

SaaS i.e. Software as a service application can be run directly from internet without any downloads or installations. A SaaS type involves email and collaboration, customer management and also involves the health-care related application. SaaS is a source of model for management of security this security which involves the application such as antivirus software.

\section{IV.CONCLUSION}

Cloud computing has many benefits. Cloud solution are simple to acquire and don't require long term contest and it are also easier to scalar. Due to cloud computing computer network become popular way to restore many network problem with efficient manner. In this paper from review it's been found that all the services provide (IaaS, PaaS, SaaS).Security provide that services. With the goal of security of services oriented architecture the security accept and issue are inherit not only with the elements that from cloud in different structure but also with an associated services as well as the way of computing is done both at the users and cloud service providers.

\section{ACKNOWLEDGEMENT}

It gives us great pleasure in presenting a paper titled "Survey on Services on Cloud Computing". We wish to thanks all the people who given or provided invaluable most important knowledge and support to complete this paper. Guidance and motivation gave by these people helpful to making a paper successful completion.

We especially thank our guide Prof. Sayali Shinde who gives us guidance about the creation of survey paper generation and most important they give or provide encouragement up to completion of the paper. We also thankful to our head of the department Computer Science and Engineering Prof. Ashish Patil sir to encourage us and they provided need assistant, suggestions to complete the paper. We would like to thanks our respected principal Dr. Jalindar Patil sir. We are extremely thankful to our all teachers and management of college for providing all the materials requires publishing the paper.

\section{REFERENCES}

[1] Mladen A. Vouk- Journal of Computing and Information Technology - CIT 16, 2008, 4, 235-246 doi:10.2498/ cit.1001391

[2] IlangoSriram-(Department of Computer Science University of Bristol UK), Alikahageh- Hussein-(Cloud Computing CoLaboratory School of Computer Science University of St Andrews St Andrews, UK)

[3] Monjur Ahmed and Mohammad Ashraf Hussein- International Journal of Network Security \& Its Applications (IJNSA)

[4] Mini Singh Ahuja1, Randeep Kaur2 and Dinesh Kumar3 International Journal of Hybrid Information Technology Vol.8, No.3 (2015), pp.297-306 http://dx.doi.org/10.14257/ijhit.2015.8. 3.26

[5] Rabi Prasad Padhy Senior Software Engineering Oracle India Prt. Ltd Bangalore, India

[6] ManasranjanPatra- Associate Professor Dept. of Computer Science Berhampur University, India.

[7] Suresh Chandra Satapathy- Head of Department and Professor Department of Computer Science and Engineering ANITS, Sanivasala, India.

\section{BIOGRAPHIES}

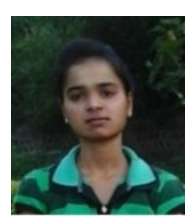

Tejaswini Ashok Kharat Student, AGTI Daulatarao Aher College of Engineering, Karad, Maharashtra, India.

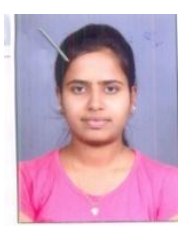

Shruti Ramchandra Kadam Student, AGTI Daulatarao Aher College of Engineering, Karad, Maharashtra, India. 